\section{An algorithm to safely manage oral food challenge in an office-based setting for children with multiple food allergies}

\author{
Nathalie Cottel ${ }^{1}$, Aïcha Dieme ${ }^{2}$, Véronique Orcel ${ }^{3}$, Yannick \\ Chantran $^{4}$, Mélisande Bourgoin-Heck ${ }^{1}$ and Jocelyne Just ${ }^{1 *}$ \\ ${ }^{1}$ Allergology Department, Hospital A. Trousseau, Sorbonne University, AP-HP, Paris, France \\ ${ }^{2}$ Pediatry Department, Hospital A. Paré, AP-HP, Boulogne-Billancourt, France \\ ${ }^{3}$ General Practitioner Department, Paris-Est Créteil University, Créteil, France \\ ${ }^{4}$ Pharm D, Immunology Department, Biological Allergology Unit, Hôpital A. Trousseau, Sorbonne \\ University, AP-HP, Paris, France
}

\section{Abstract}

Background: In France, from $30 \%$ to $35 \%$ of children suffer from multiple food allergies (MFA). The gold standard to diagnosis a food allergy is the oral food challenge (OFC) which is conducted in a hospital setting due to risk of anaphylaxis.

The aim of this study was to evaluate an algorithm to predict OFCs at low risk of anaphylaxis that could safely be performed in an office-based setting.

Methods: Children with MFA and at least one open OFC reactive or non-reactive to other allergens were included. The algorithm was based on multiple clinical and biological parameters related to food allergens, and designed mainly to predict "low-risk" OFCs i.e., practicable in an office-based setting. The algorithm was secondarily tested in a validation cohort.

Results: Ninety-one children (median age 9 years) were included; $94 \%$ had at least one allergic comorbidity with an average of three OFCs per child. Of the 261 OFCs analyzed, most (192/261, $74 \%$ ) were non-reactive. The algorithm failed to correctly predict 32 OFCs with a potentially detrimental consequence but among these only three children had severe symptoms. One hundred eighty-four of the 212 "low-risk" OFCs, $(88 \%)$ were correctly predicted with a high positive predictive value $(87 \%)$ and low negative predictive value $(44 \%)$. These results were confirmed with a validation cohort giving a specificity of $98 \%$ and negative predictive value of $100 \%$.

Conclusion: This study suggests that the algorithm we present here can predict "low-risk" OFCs in children with MFA which could be safely conducted in an office-based setting. Our results must be confirmed with an algorithm-based machine-learning approach.

\section{More Information}

*Address for Correspondence:

Pr. Jocelyne Just, M.D., Ph.D. Service d'Allergologie, Hôpital A.Trousseau, Sorbonne University, 26 Avenue du Dr. Arnold Netter, 75012 Paris, France, Tel: +331717368 47; Email: jocelyne.just@aphp.fr

Submitted: August 02, 2021 Approved: August 10, 2021 Published: August 11, 2021

How to cite this article: Cottel N, Dieme A, Orcel V, Chantran Y, Bourgoin-Heck M, et al. An algorithm to safely manage oral food challenge in an office-based setting for children with multiple food allergies. Arch Asthma Allergy Immunol. 2021; 5: 030-037.

DOI: 10.29328/journal.aaai.1001027 ORCiD: orcid.org/0000-0002-5646-2429

Copyright: @ 2021 Cottel N, et al. This is an open access article distributed under the Creative Commons Attribution License, which permits unrestricted use, distribution, and reproduction in any medium, provided the original work is properly cited.

Keywords: Multiple food allergies; Children; Specific IgE; Allergen component; Algorithm

Check for updates

OPEN ACCESS

\section{Introduction}

Food allergy (FA) management in children is a current public health problem. The prevalence of FAs has been increasing over the last 30 years, mainly in industrial countries, and affects around $10 \%$ of the population today [1]. Between 2010 and 2011, 2.4\% of children in the USA were identified as having multiple food allergies (MFA) (i.e., 30.4\% of all children with FA) and about 3\% had a history of an anaphylactic accident [2]. Similarly, in France, 30\% to 35\% of children with FAs suffer from MFA $[3,4]$.
In Europe, the number of anaphylactic accidents is rising especially for boys under 5 years [5]. Anaphylaxis is the first symptom of an FA in $30 \%$ to $60 \%$ of cases for children [6].

In France, the most common FAs in children are cow's milk, eggs, peanuts and nuts [7]. Some of these children have an atopic history with asthma, atopic dermatitis or allergic rhinitis. The presence of these allergic comorbidities, especially asthma, could increase the risk of anaphylaxis [8-10]. MFA in children also increases the risk of a severe anaphylactic reaction [11]. 
Medical history and measurement of specific-IgE (s-IgE) levels toward crude allergen and allergen components play an important role in assessing MFA especially in case of cross reactivity of allergens (for example nuts or legumes) [12].

An oral food challenge (OFC) remains the gold standard to distinguish allergic sensitization from an FA. However, not only are OFCs time consuming and costly, but they generally need to be conducted in a hospital setting with easy access to an intensive care unit due to the risk of anaphylaxis.

Several models (based on s-IgE levels, prick tests, and clinical history) have been proposed to predict the outcome of an OFC [13]. However, the relationship between prick tests, s-IgE levels and clinical severity is currently unclear [13]. Finally, cellular diagnostic tests, such as a basophil activation test, could replace an OFC in some cases but are expensive and require specialized laboratories [14].

To date, the European Academy of Allergy and Clinical Immunology (EAACI) and the American Academy of Allergy, Asthma and Immunology (AAAAI) estimate that around 10 000 diagnostic OFCs have been safely conducted worldwide after a benefit/risk ratio estimation for each child by medical staff $[13,15]$. However, hospital-based OFCs cause considerable stress for the children, require the parents to be present at the hospital which implies they take time off work, and incur other costs linked to transport and hospital staff. These elements should all be taken into consideration before deciding to run an OFC $[16,17]$.

In the USA, OFCs are sometimes conducted at outpatient allergy clinics, i.e., not in a hospital center (high resource infusion center) which could constitute a time- and costeffective way of managing OFCs at "low risk" of anaphylaxis [17].

The aim of the study we report here was to evaluate the use of a new algorithm based on history of FA for each relevant allergen and biological parameters (mainly s-IgE levels for the crude allergen and available relevant allergen components) to identify children with MFAs at low risk of anaphylactic reaction as a triage approach for performing OFCs in an officebased setting.

\section{Methods}

\section{Design}

This was a retrospective single-center study conducted in the pediatric allergy center of Armand Trousseau Hospital between January 2010 and December 2018. The robustness of the algorithm was validated in a prospective study between January 2019 and November 2020.

Inclusion criteria: We considered for inclusion all children with MFA with at least two IgE-mediated FAs defined as an anaphylactic accident in real life, and/or a positive open $\mathrm{OFC}$, and at least one $\mathrm{OFC}$ reactive or non-reactive to another allergen. The s-IgE levels for the crude allergen or the relevant s-IgE levels for the allergen component, if marketed, had to be available for the allergens for which the OFC results were predicted.

Exclusion criterion: The exclusion criteria were the absence of biological parameters (mainly s-IgE levels contemporary of OFC) or s-IgE levels $<0.1 \mathrm{kU} / \mathrm{L}$ for the allergen tested during OFC and patient treated by omalizumab at the time of the OFC.

Parameters collected for each patient were:

Demographic features: age at first OFC; gender.

- Atopic comorbidities, i.e., asthma, allergic rhinitis, atopic dermatitis and the severity of each comorbidity defined respectively by Global Initiative for Asthma (GINA) guidelines [18], Allergic Rhinitis and its Impact of Asthma (ARIA) consensus [19] and Scoring atopic dermatitis (SCORAD) [20].

- History of FA for each relevant allergen trigger in real life: time of reaction; route of allergen (inhaled or ingested); threshold of allergen; and severity of FA symptoms. Symptom severity was defined as follows: (1) subjective symptoms as facial itching and/or subjective gastrointestinal symptoms (mild abdominal pain and/or nausea); (2) mild-to-moderate symptoms with one or two associated symptoms including oral allergy syndrome, mild gastro-intestinal symptoms, conjunctivitis and/or rhinitis, rash, urticarial and/or subcutaneous angioedema [21]; (3) severe reactions including systemic allergic reaction (symptoms involving two organs), laryngeal angioedema, acute asthma, anaphylactic shock or treatment by intramuscular epinephrine [21].

- Biological parameters: total IgE and s-IgE levels for the crude allergen and available relevant allergen components (Thermofischer, Uppsala, Sweden) and their kinetics since food eviction.

- In view of the great diversity of protein content according to the food ingested (animal origin, vegetable etc.) milligrams of food ingested were used to define the cumulative eliciting dose (ED) during the OFC. The protein content of each food is presented in the Table.

- The OFC result was defined by the cumulative ED threshold as follows:

o Non-reactive OFC (1) at a high cumulative ED of $\geq 4000 \mathrm{mg}$ of allergen (chosen according to appropriate portion for age); (2) at a low cumulative ED of $<2000 \mathrm{mg}$ of allergen (to eliminate allergic reaction at low dose in current life)

o Reactive OFC (1) at a high cumulative ED of $\geq 2000$ $\mathrm{mg}$; (2) at a low cumulative ED of $<2000 \mathrm{mg}$. 
- Severity of allergic reaction was evaluated as defined above.

We created an algorithm (copyright application filed with the Institut National de la Propriété Intellectuelle) based on all these parameters except for the OFC results. The algorithm was analyzed to determine if it could be used to predict OFC result thresholds in a personalized manner.

The errors (mismatches between the algorithm prediction and OFC results) were analyzed in terms of threshold (high and low cumulative ED) and severity of allergic reaction during OFC. Any error involving a very low cumulative ED $(<300 \mathrm{mg}$ ) was specifically analyzed to identify potentially detrimental clinical consequences.

Finally, we defined OFC at "low risk" (considered to be practicable in an office-based setting) and at "high risk" (impracticable in an office-based setting), and as non-reactive or reactive OFC without severe allergic symptoms during an OFC or reactive OFC with severe symptoms, respectively.

\section{Validation cohort}

To validate the robustness of the algorithm, we tested it on a validation cohort with the same inclusion and exclusion criteria. We identified and analyzed OFC results predicted as "low-risk" by the algorithm.

\section{Statistical analysis}

The characteristics of the population were expressed as percentages for categorical variables or median values with interquartile range (IQR) for continuous variables (total IgE levels). We fully describe the algorithm prediction mistakes and differentiated objective and subjective reactions and the cumulative ED dose. The sensitivity, specificity, positive predictive values and negative predictive values for this study were calculated with Excel $^{\circledR}\left(\right.$ Microsoft $\left.^{\circledR}\right)$ as described by Akobeng AK in Acta Paediatr. 2007; 96: 338-41. All the statistics were produced by two separate operators.

\section{Ethics}

This study was conducted according to the reference methodology MR-004 with the French Data Protection Authority (CNIL) (Authorization no. MR2315120320). All the patients or parents had received an information note and could oppose the use of their children's personal data. No refusal for participation was received.

\section{Results}

\section{Characteristics of the study population}

During the study period, 332 OFCs were reported. Thirtyseven OFCs with s-IgE levels $<0.1 \mathrm{kU} / \mathrm{L}$ were excluded from analysis and another 34 because the s-IgE levels for a currently marketed allergen component were not available.

Finally, 261 OFCs performed in 102 patients were included.
The characteristics of the study population are reported in Table 1. Sixty-two of the population overall (61\%) were boys, and the median age was 9 years $( \pm 2.17)$. All but five children $(95 \%)$ had at least one allergic comorbidity.

\section{OFC description}

The children underwent an average of three OFCs. Most of the OFCs were non-reactive (192/261, 74\%). Allergen distribution during the OFC is reported in Figure 1. The predominant allergens that were reactive during the OFC were peanut (6\%) and cashew (4\%).

\section{Comparison between the algorithm prediction and the OFC results}

All the algorithm predictions are shown in the Table 2. The algorithm correctly predicted reactive OFCs in 33/69 (48\%) of the patients and non-reactive OFCs in 96/192 (50\%). Thirty-two of the incorrect predictions $12 \%$ of the total predictions) were associated with potentially detrimental clinical consequences.

\begin{tabular}{|c|c|}
\hline \multicolumn{2}{|c|}{ Demographic features } \\
\hline Gender (Male) $(n / \%)$ & $62 / 61$ \\
\hline Age, years, median $\pm S D$ & $9 \pm 2.17$ \\
\hline \multicolumn{2}{|c|}{ Allergic comorbidities } \\
\hline At least one $(n / \%)$ & $86 / 95$ \\
\hline Asthma ${ }^{a}(n / \%)$ & $73 / 80$ \\
\hline Mild-to-moderate persistent & $69 / 76$ \\
\hline Severe persistent & $4 / 4.4$ \\
\hline Active atopic dermatitis ${ }^{b}(n / \%)$ & $28 / 31$ \\
\hline Mild-to-moderate & $17 / 19$ \\
\hline Severe & $11 / 12$ \\
\hline Allergic rhinitis ${ }^{c}(n / \%)$ & $55 / 60$ \\
\hline Mild-to-moderate & $49 / 54$ \\
\hline Severe & $6 / 7$ \\
\hline \multicolumn{2}{|c|}{ Food allergy } \\
\hline History of anaphylaxis (n/\%) & $48 / 53$ \\
\hline $\begin{array}{c}\text { History of allergic reaction on inhalation } \\
\text { of allergen }(n / \%)\end{array}$ & $4 / 4$ \\
\hline \multicolumn{2}{|c|}{ Biological parameters } \\
\hline Total IgE median $\pm \mathrm{SD}(\mathrm{kU} / \mathrm{L})$ & $585 \pm 1740$ \\
\hline $\begin{array}{l}\text { aaccording to GINA } 2019 \text { guidelines }{ }^{18} \\
\text { bseverity symptoms evaluated with a scc } \\
\text { c as defined in ARIA consensus }{ }^{20}\end{array}$ & \\
\hline
\end{tabular}

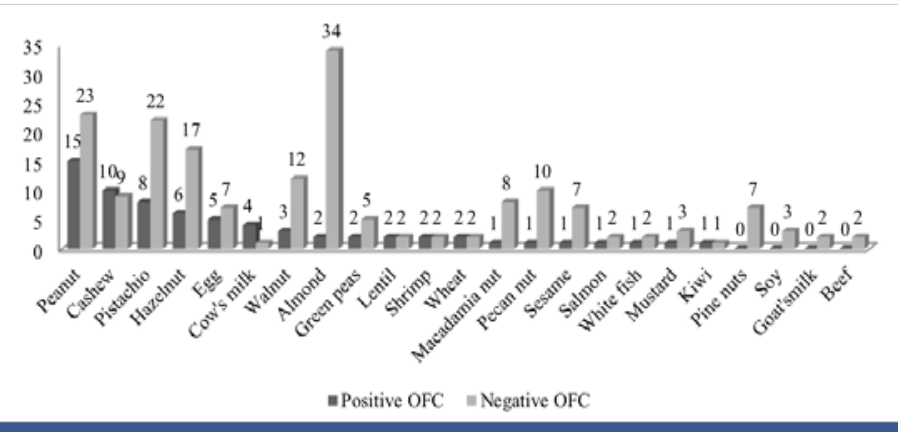




\begin{tabular}{|c|c|c|c|c|}
\hline & \multicolumn{4}{|c|}{ OFC $^{1}$ results } \\
\hline & $\begin{array}{c}\text { Non-reactive } \\
\text { OFC }^{a} \\
\text { (> } 4000 \mathrm{mg})\end{array}$ & $\begin{array}{l}\text { Non-reactive OFC a low cumulative } \\
\qquad \operatorname{ED}^{\mathrm{b}}(<2000 \mathrm{mg})\end{array}$ & $\begin{array}{l}\text { Reactive OFC }{ }^{\mathrm{a}} \text { at high cumulative } \\
\qquad \mathrm{ED}^{\mathrm{b}}(\geq 2000 \mathrm{mg})\end{array}$ & $\begin{array}{l}\text { Reactive OFC a low cumulative } \\
\qquad \mathrm{ED}^{\mathrm{b}}(<2000 \mathrm{mg})\end{array}$ \\
\hline \multicolumn{5}{|l|}{ Algorithm prediction } \\
\hline Non-reactive OFC ${ }^{a}(>4000 \mathrm{mg}$ ) & 66 & 0 & 4 & 7 \\
\hline $\begin{array}{l}\text { Non-reactive OFC a at low cumulative } \\
\qquad \operatorname{ED}^{\mathrm{b}}(<2000 \mathrm{mg})\end{array}$ & 0 & 30 & 0 & 0 \\
\hline $\begin{array}{l}\text { Reactive OFC a at high cumulative ED } \\
\qquad(\geq 2000 \mathrm{mg})\end{array}$ & 73 & 0 & 11 & 21 \\
\hline $\begin{array}{l}\text { Reactive OFC at low cumulative } \mathrm{ED}^{\mathrm{b}} \\
\qquad(<2000 \mathrm{mg})\end{array}$ & 23 & 0 & 4 & 22 \\
\hline
\end{tabular}

Analysis of the 32 errors in OFC prediction with potentially detrimental clinical consequences

Among the 32 errors, 29 (91\%) had no detrimental consequence: 12 (38\%) were reactive with subjective allergic symptoms including four reactive at very low cumulative ED (Table 3); and 17 (53\%) were reactive with mild-to-moderate symptoms including six reactive at very low cumulative ED (Table 3). Finally, only three (9\%) of the 32 OFC errors were reactive with severe allergic symptoms, among which only one (3\%) required epinephrine injection (Table 4 ).

\section{Analysis of prediction of "low-risk" OFC practicable in an office-based setting}

The algorithm correctly identified 184 of the 212 (88\%) "low-risk" OFCs (Table 5). Finally, the algorithm had a sensitivity of $87 \%$, a specificity of $44 \%$, a positive predictive value of $87 \%$, and a negative predictive value of $44 \%$ for the prediction of low-risk OFC.

\section{Validation cohort}

During the second study period, 132 OFCs were identified by the algorithm as "low-risk" in 73 patients. The characteristics of this validation cohort are reported in Table 6. Sixty-one (84\%) were boys with a median age of 8.5 years $( \pm 3.7)$. Their clinical characteristics are reported in Table 7 . The main allergens introduced during the OFCs were brazil nut, macadamia nut, and pine nut (Supplemental Figure 1).

Only two children were reactive during their OFC with subjective allergic symptoms (mild and isolated abdominal pain for one child, and nonobjective labial edema for the other). The algorithm correctly predicted "low-risk" OFCs in $130 / 132(98 \%)$ with a specificity of $98 \%$ and a negative predictive value of $100 \%$.

\section{Discussion}

The algorithm we introduce here correctly predicted that an OFC could be safely managed in an office-based setting in $184 / 212$ (88\%) of the children with MFA in our population. Finally, only three of the incorrect predictions underestimated the risk in children who reacted severely to the OFC, and 10 errors consisted of subjective or mild symptoms at very low cumulative ED.

\section{Population characteristics}

Our study population had a high rate of history of anaphylaxis (53\%) and multiple allergic comorbidities (95\%). In the same manner, Sindher, et al. [22] described a cohort of 427 children with MFA who presented a history of anaphylaxis and intramuscular epinephrine injection [22]. In our study, the allergens tested at hospital were mainly peanut (15\%) and nuts: almond (14\%), pistachio (12\%), hazelnut $(9 \%)$ and cashew (7\%). Egg and cow's milk represented only $5 \%$ and $2 \%$, respectively. Most of the OFCs were conducted for tree nuts due to cross reactivity between this family and peanuts $[23,24]$.

\section{Characteristics of OFC results}

The rate of reactive OFCs in our population $(26 \%)$ is similar to that found in the literature (17\%) with $20 \%$ to $40 \%$ of patients presenting severe reactions or reactions at low cumulative ED [15]. In our study, peanuts and cashew were the most reactive foods (in number and severity). Sindher, et al. [22], in a similar cohort, also found that pecan nuts and cashews were the most common reactive OFCs. Furthermore, and similarly to our results, no reactive OFC was found with almond.

\section{Algorithm prediction of "low risk" OFC}

Although OFC is the gold standard of the diagnosis of FA, it is time consuming, costly and stressful. Stress is a major cofactor of anaphylaxis and can cause subjective symptoms making the OFC outcome difficult to interpret. Consequently, the PRACTALL guidelines (endorsed by both the EAACI and the AAAAI) do not exclude the development of office-based OFCs performed by experienced allergists able to deal with an allergic accident: an experienced allergist could assess risk factors before beginning the OFC $[13,25]$ and would know that the patient should be monitored for 2 hours to detect any case of delayed reaction $[13,15]$.

The algorithm we present here takes into account multiple 
Table 3: Description of errors between the algorithm prediction and subjective and mild-to-moderate objective allergic reaction during oral food challenge 12 errors between the algorithm and subjective allergic reaction during oral food challenge

\begin{tabular}{|c|c|c|c|}
\hline \multicolumn{4}{|c|}{ Very low cumulative ED during OFCa } \\
\hline Patient 1 & Cashew & Pharynx itching & Antihistamine \\
\hline Patient 2 & Cashew & Pharynx itching & Antihistamine \\
\hline Patient 3 & Pistachio & Pharynx itching & Antihistamine \\
\hline Patient 4 & Pistachio & Pharynx itching & Antihistamine \\
\hline Patient 5 & Hazelnut & Pharynx itching and mild abdominal pain & Antihistamine \\
\hline \multicolumn{4}{|c|}{ Low cumulative ED during $\mathrm{OFC}^{\mathrm{b}}$} \\
\hline Patient 1 & Peanut & Pharynx itching and nausea & Antihistamine and steroid \\
\hline Patient 2 & Peanut & Nasal, auricular and ocular itching & Antihistamine \\
\hline Patient 3 & Peanut & Nausea and mild abdominal pain & Antihistamine \\
\hline Patient 4 & Pistachio & Pharynx itching and mild abdominal pain & Antihistamine \\
\hline Patient 5 & Almond & Pharynx itching & Antihistamine \\
\hline \multicolumn{4}{|c|}{ High cumulative ED during OFC ${ }^{c}$} \\
\hline Patient 1 & Peanut & Pharynx itching & Antihistamine \\
\hline Patient 1 & Hazelnut & Pharynx itching & None \\
\hline \multicolumn{4}{|c|}{17 errors between the algorithm prediction and mild-to-moderate objective allergic reaction during oral food challenge } \\
\hline \multicolumn{4}{|c|}{ Very low cumulative ED during OFC ${ }^{a}$} \\
\hline Patient 1 & Raw egg & Mild gastro-intestinal symptoms & Antihistamine \\
\hline Patient 2 & Cashew & OAS $\pi$ & Antihistamine \\
\hline Patient 3 & Pistachio & Abdominal pain and mild urticaria & None \\
\hline Patient 4 & Hazelnut & Rhinitis & Antihistamine \\
\hline Patient 5 & Salmon & OAS & Antihistamine \\
\hline Patient 6 & Mustard & Mild gastro-intestinal symptoms & Antihistamine \\
\hline \multicolumn{4}{|c|}{ Low cumulative ED during $\mathrm{OFC}^{b}$} \\
\hline Patient 1 & Egg & OAS & Antihistamine and steroid \\
\hline Patient 2 & Peanut & Mild gastro-intestinal symptoms & Antihistamine and steroid \\
\hline Patient 3 & Almond & Urticaria & None \\
\hline Patient 4 & Cashew & Urticaria and mild gastro-intestinal symptoms & Antihistamine and steroid \\
\hline Patient 5 & Cashew & Mild gastro-intestinal symptoms & Antihistamine and steroid \\
\hline Patient 6 & Pistachio & Urticaria & Antihistamine \\
\hline Patient 7 & Lentils & Subcutaneous angioedema & Antihistamine \\
\hline \multicolumn{4}{|c|}{ High cumulative ED during $\mathrm{OFC}^{\mathrm{c}}$} \\
\hline Patient 1 & Peanut & OAS & Antihistamine and steroid \\
\hline Patient 2 & Hazelnut & OAS and conjunctivitis & Antihistamine \\
\hline Patient 3 & Macadamia Nut & Rhinitis and conjunctivitis & Antihistamine \\
\hline Patient 4 & Avocado & Rash on face, mild gastro-intestinal symptoms & Antihistamine and steroid \\
\hline
\end{tabular}

Table 4: Description of 3 errors between algorithm prediction and severe allergic reaction during oral food challenge.

Low cumulative threshold ED during OFC ${ }^{a}$

\begin{tabular}{c|c|c|c} 
Patient 1 & Peanut & OASc and extensive urticaria and asthma & $\begin{array}{c}\text { Intravenous antihistamine and intravenous steroid } \\
\text { Two injections of epinephrine }\end{array}$ \\
\hline Patient 1 & Cashew & OAS and gastro-intestinal symptoms & Intravenous antihistamine and intravenous steroid \\
\hline
\end{tabular}

High cumulative threshold ED during $\mathrm{OFC}^{b}$

\begin{tabular}{l|l|l|l|l} 
Patient 1 & Egg & OAS and gastro-intestinal symptoms & Oral antihistamine and Intravenous antihistamine and intravenous steroid
\end{tabular} a Low/ ${ }^{\mathrm{H}} \mathrm{High}$ cumulative threshold elicting dose (ED) during oral food challenge (OFC): $<2000 \mathrm{mg} />2000 \mathrm{mg}$ 'OAS: oral allergy syndrome.

Table 5: Comparison between the algorithm prediction of "low risk" and "high risk" allergic reaction during oral food challenge.

\begin{tabular}{|c|c|c|}
\hline & \multicolumn{2}{|c|}{ OFC results } \\
\hline & "Low risk OFC"a & "High risk OFC"b \\
\hline Algorithm prediction & & \\
\hline "Low risk OFC"a & $\mathbf{1 8 4}$ & 28 \\
\hline "High risk OFC"b & 27 & $\mathbf{2 2}$ \\
\hline
\end{tabular}

${ }^{a}$ possibility or ${ }^{b}$ not of performing OFC in outpatient medical office in safety manner The algorithm predicts OFC results: correctly (Bold), incorrectly with (italics) or without detrimental consequence (unspecified font). factors found in the literature: specific allergen reactivity (mentioned above), percentage of cross reactivity especially with nuts [26], but also s-IgE levels towards crude allergens and allergen components and their kinetics since the eviction of food. Biological tools could help to predict OFC results on a population scale but not on an individual scale. Dunn Galvin, et al. [27] confirmed the advantage of biological tools (s-IgE levels and/or skin tests) in a population of children with a clinical history of anaphylaxis. In a large study (2272 OFCs 


\begin{tabular}{|c|c|}
\hline \multicolumn{2}{|l|}{ Demographic features } \\
\hline Gender (Male) (n/\%) & $61 / 84$ \\
\hline Age, years, median \pm SD & $8.5 \pm 3.7$ \\
\hline \multicolumn{2}{|l|}{ Allergic comorbidities } \\
\hline At least one (n/\%) & $71 / 97$ \\
\hline Asthma ${ }^{a}(n / \%)$ & $48 / 66$ \\
\hline Mild-to-moderate persistent & $48 / 66$ \\
\hline Severe persistent & l \\
\hline Active atopic dermatitis ${ }^{b}(n / \%)$ & $52 / 71$ \\
\hline Mild-to-moderate & $52 / 71$ \\
\hline Severe & l \\
\hline Allergic rhinitis ${ }^{c}(n / \%)$ & $47 / 64$ \\
\hline Mild-to-moderate & $28 / 38$ \\
\hline Severe & $19 / 26$ \\
\hline \multicolumn{2}{|l|}{ Food allergy } \\
\hline History of anaphylaxis (n/\%) & $42 / 58$ \\
\hline History of allergic reaction on inhalation of allergen $(n / \%)$ & $2 / 3$ \\
\hline \multicolumn{2}{|l|}{ Biological parameters } \\
\hline Total $\lg \mathrm{E}$ median $\pm \mathrm{SD}(\mathrm{kU} / \mathrm{L})$ & $637 \pm 1111$ \\
\hline $\begin{array}{l}\text { aaccording to GINA } 2019 \text { guidelines }{ }^{18} \\
\text { bseverity symptoms evaluated with a score of SCORAD }^{19} \\
\text { 'as defined in ARIA consensus }{ }^{20}\end{array}$ & \\
\hline
\end{tabular}

Table 7: Comparison of clinical characteristics between study population and validation cohort.

\begin{tabular}{|c|c|c|c|c|c|}
\hline & \multicolumn{2}{|c|}{ Initial cohort $(n=91)$} & \multicolumn{2}{|c|}{ Validation cohort $(n=73)$} & $p$ - value \\
\hline \multicolumn{6}{|l|}{ Demographic features } \\
\hline Gender (Male) (n/\%) & 62 & 61 & 61 & 84 & $0.02 *$ \\
\hline Age, years, median $\pm S D$ & 9 & 2.17 & 61 & 84 & 0.83 \\
\hline \multicolumn{6}{|l|}{ Allergic comorbidities } \\
\hline At least one $(n / \%)$ & 86 & 95 & 71 & 97 & 0.39 \\
\hline Asthma (n/\%) & 73 & 80 & 48 & 66 & $0.04^{*}$ \\
\hline Mild-to-moderate persistent & 69 & 76 & 48 & 66 & 0.16 \\
\hline Severe persistent & 4 & 4.4 & & & \\
\hline Active atopic dermatitis ( $\mathrm{n} / \%)$ & 28 & 31 & 52 & 71 & $<0.01^{*}$ \\
\hline Mild-to-moderate & 17 & 19 & 52 & 71 & $<0.01^{*}$ \\
\hline Severe & 11 & 12 & & & \\
\hline Allergic rhinitis (n/\%) & 55 & 60 & 47 & 64 & 0.6 \\
\hline Mild-to-moderate & 49 & 54 & 28 & 38 & 0.07 \\
\hline Severe persistent & 6 & 7 & 19 & 26 & $<0.01^{*}$ \\
\hline \multicolumn{6}{|l|}{ Food allergy } \\
\hline History of anaphylaxis (n/\%) & 48 & 53 & 42 & 58 & 0.54 \\
\hline History of allergic reaction on inhalation of allergen $(n / \%)$ & 4 & 4 & 2 & 3 & 0.89 \\
\hline \multicolumn{6}{|l|}{ Biological parameters } \\
\hline Total $\operatorname{lgE}$ median $\pm \mathrm{SD}(\mathrm{kU} / \mathrm{L})$ & 585 & 1740 & 637 & 1111 & 0.32 \\
\hline
\end{tabular}

Values are expressed as numbers or medians [IQ]. $p$ values $<0.05$ are boldface for two-groups comparisons of qualitative or quantitative variables by using Chi-square test and Student test.

for cow's milk, egg, peanuts and wheat) the authors found that high s-IgE levels were correlated with a high incidence of anaphylaxis [28]. Nevertheless, the PRACTALL guidelines do not include a correlation between the s-IgE levels and severity of allergic reaction during OFC. Furthermore, it is well known that the kinetics of s-IgE levels, age and duration of eviction of food allergens could be associated with the severity of reaction during OFC [15]. Finally, in our study we found that the algorithm's prediction of "low-risk" OFC was correct for $184 / 212$ (88\%) OFCs with a high positive predictive value ( $87 \%$ ) but low negative predictive value $(44 \%)$. These results are better than another retrospective study [29] that predicted only $24 \%$ of OFC outcomes when taking into account age, medical history of reactions, a low ED, a rapid reactive outcome, and s-IgE levels [13,29].

\section{Improvement of algorithm to ensure safety for "low- risk" OFC prediction}

In our study, the OFC results could be predicted by means of s-IgE levels toward the allergen component. This finding has already been reported in the literature: s-IgE levels toward allergen components were better at predicting OFC results than s-IgE levels toward the crude allergen [14]. In the future, with the new trends in molecular biology, novel s-IgE levels toward allergen components could probably improve the algorithm's prediction. Machine learning could 
also probably boost the algorithm's prediction by including patient data and information from medical literature [30]. In the field of asthma, some authors are already evaluating machine learning to improve patient management and reduce exacerbations [31].

The perspective of this study was a machine-learning technologies that could upgrade the specificity and positive predictive value of the algorithm and secondly large cohort of MFA to test the validity of the software in real life condition. Secondly, to improve the safety of prediction of reactive OFCs at a very low cumulative ED, we are planning a study to evaluate office-based OFCs in three consultations: one with a very low cumulative $E D$, a second one with a low cumulative ED if the first was non-reactive, and finally a third one with a high cumulative ED if the second was non-reactive [13,15,22], as Bird, et al. propose in their peanut challenge protocol paper [32].

The algorithm we present here could be interesting in "low-risk" situations since it predicted OFC results with very good specificity in a validation cohort. These results support the performance of algorithm-predicted "low-risk" OFCs in an office-based setting.

\section{Strengths and limits}

The main strength of the study is that it was conducted in a well characterized cohort of children with MFA. However, the OFCs were performed as open label which may have led to misinterpretation of subjective symptoms compared to double blind OFCs $[13,15]$. For example, the PRACTALL guidelines state that an OFC can be continued in the case of a temporary urticaria or if a stressed child vomits [15]. Another limit of our study, was that the OFCs were not conducted with very high doses (i.e., more than $2200 \mathrm{mg}$ cumulative ED reaction). Finally, our study was a retrospective single-center study. Nevertheless, the center is a recognized tertiary care center and our prospective validation cohort supports the algorithm with an excellent specificity.

\section{Conclusion}

Our results are an encouraging step towards practicing "low-risk" OFCs in children with MFA in an office-based setting. Nevertheless, the results must be confirmed in a prospective, double-blind, placebo controlled multicenter study with algorithm-based machine learning.

\section{Acknowledgments}

We thank RemyCouderc, PhD and Marie-Ange Selva, ME for technical assistance, and Dr Lambert Nathalie, MD, Dr AMAT Flore, MD, PhD, Dr. Paluel-Marmont Colombe, MD and Dr Tallon Pauline, MD for their cooperation.

\section{Statements of ethics}

This study was conducted according to the reference methodology MR-004 with the French Data Protection Authority (CNIL) (Authorization no. MR2315120320). All the patients or parents had received an information note and could oppose the use of their children's personal data. No refusal for participation was received.

\section{Conflict of interest}

Nathalie Cottel, MD, Aïcha Dieme, MD, Véronique Orcel, Yannick Chantran, PharmD and Melisande Bourgoin-Heck, MD report no competing interests.

Jocelyne Just, MD, PhD-is on the boards for ALK Abello, Stallergenes Green, AstraZeneca, and Novartis; and has received research support from Novartis.

\section{Author contributions}

Concept and design: Jocelyne Just.

Acquisition, analysis, or interpretation of data: Nathalie Cottel, Aïcha Dieme, Véronique Orcel and Jocelyne Just.

Drafting of the manuscript: Nathalie Cottel, Aïcha Dieme and Jocelyne Just.

Statistical analysis: Nathalie Cottel and Aïcha Dieme.

Revising and final approval: Yannick Chantran, Mélisande Bourgoin-Heck and Jocelyne Just.

Data availability statement: The data that support the findings of this study are available from the corresponding author upon reasonable request.

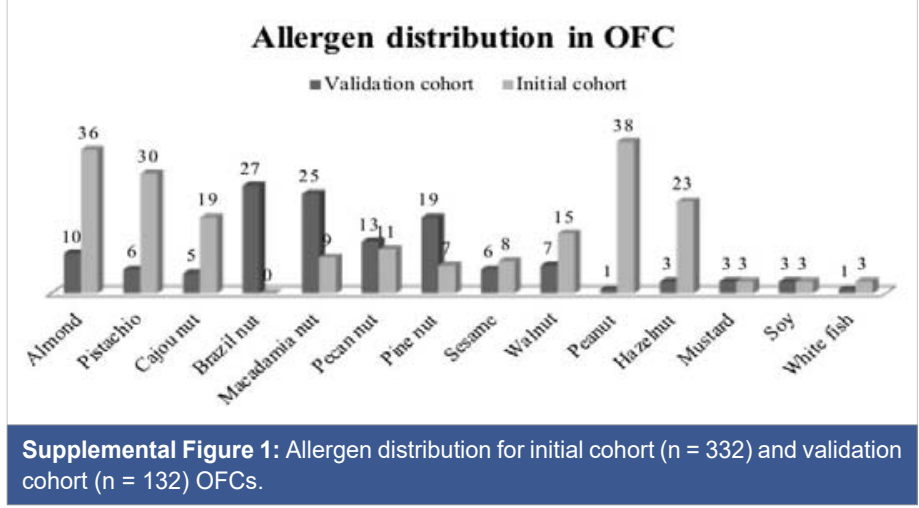

\section{References}

1. Sicherer SH, Sampson HA. Food allergy: A review and update on epidemiology, pathogenesis, diagnosis, prevention, and management. J Allergy Clin Immunol. 2018; 141: 41-58.

PubMed: https://pubmed.ncbi.nlm.nih.gov/29157945/

2. Gupta RS, Springston EE, Warrier MR, Smith B, Kumar R, et al. The Prevalence, Severity, and Distribution of Childhood Food Allergy in the United States. Pediatrics. 2011; 128: 9-17.

PubMed: https://pubmed.ncbi.nlm.nih.gov/21690110/

3. Deschildre A, Lejeune S, Roussel J, Pouessel G, Mordacq C, et al. Polyallergie et risque d'accident allergique aigu grave. Rev Fr Allergol. 2018; 58: 167-169. 
4. Juchet $A$, Chabbert-Broué $A$. Les allergies alimentaires multiples de l'enfant. Rev Fr Allergol. 2013; 53: 523-527.

5. Turner PJ, Gowland MH, Sharma V, lerodiakonou D, Harper N, et al Increase in anaphylaxis-related hospitalizations but no increase in fatalities: An analysis of United Kingdom national anaphylaxis data 1992-2012. J Allergy Clin Immunol. 2015; 135: 956-963.

PubMed: https://pubmed.ncbi.nlm.nih.gov/25468198/

6. Pouessel G, Deschildre A. Anaphylaxie de l'enfant. Rev Fr Allergol. 2017; 57: 558-66.

7. Renaudin JM, Beaumont $P$, Sabouraud $D$, Dumond $P$, Liabeuf $V$, et al Anaphylaxie alimentaire sévère: données recueillies par le Réseau d'Allergo-Vigilance ${ }^{\circledR}(2002-2017)$ et allergènes émergents. Rev Fr Allergol. 2017; 57: 3-7.

8. Eapen AA, Lavery WJ, Siddiqui JS, Lierl MB. Oral immunotherapy for multiple foods in a pediatric allergy clinic setting. Ann Allergy Asthma Immunol. 2019; 123: 573-581.

PubMed: https://pubmed.ncbi.nlm.nih.gov/31494236/

9. Park JH, Ahn SS, Sicherer SH. Prevalence of Allergy to Multiple Versus Single Foods in a Pediatric Food Allergy Referral Practice. J Allergy Clin Immunol. 2010; 125: AB216.

10. Foong RX, du Toit G, Fox AT. Asthma, Food Allergy, and How They Relate to Each Other. Front Pediatr. 2017; 5: 89.

PubMed: https://pubmed.ncbi.nlm.nih.gov/28536690/

11. Michaud B, Amat F, Bourgoin-Heck M, Lambert N, Talon $P$, et al. Peuton remplacer un test de provocation orale par un test biologique ? Rev Fr Allergol. 2017; 57: 114-115.

12. Wang J. Management of the Patient with Multiple Food Allergies. Curr Allergy Asthma Rep. 2010; 10: 271-277.

PubMed: https://pubmed.ncbi.nlm.nih.gov/20431971/

13. Cox AL, Nowak-Wegrzyn A. Innovation in Food Challenge Tests for Food Allergy. Curr Allergy Asthma Rep. 2018; 18: 74.

PubMed: https://pubmed.ncbi.nlm.nih.gov/30377836/

14. Matricardi PM, Kleine-Tebbe J, Hoffmann HJ, Valenta R, Hilger C, et al EAACI Molecular Allergology User's Guide. Pediatr Allergy Immunol. 2016; 27: 1-250

PubMed: https://pubmed.ncbi.nlm.nih.gov/2728833/

15. Sampson HA, Gerth van Wijk R, Bindslev-Jensen C, Sicherer S, Teuber SS, et al. Standardizing double-blind, placebo-controlled oral food challenges: American Academy of Allergy, Asthma \& ImmunologyEuropean Academy of Allergy and Clinical Immunology PRACTALL consensus report. J Allergy Clin Immunol. 2012; 130: 1260-1274. PubMed: https://pubmed.ncbi.nlm.nih.gov/23195525/

16. Dyer AA, Gupta R. Epidemiology of Childhood Food Allergy. Pediatr Ann. 2013; 42: 101-5.

PubMed: https://pubmed.ncbi.nlm.nih.gov/23718236/

17. Simberloff T, Parambi R, Bartnikas LM, Broyles AD, Hamel V, et al Implementation of a Standardized Clinical Assessment and Management Plan (SCAMP) for Food Challenges. J Allergy Clin Immunol Pract. 2017; 5: 335-344.

PubMed: https://pubmed.ncbi.nlm.nih.gov/27373725/

18. Global Initiative for Asthma. Global Strategy for Asthma Management and Prevention, 2019. www.ginasthma.org

19. Braun JJ, Devillier $P$, Wallaert $B$, Rancé $F$, Jankowski $R$, et al. Recommandations pour le diagnostic et la prise en charge de la rhinite allergique (épidémiologie et physiopathologie exclues). Rev Mal
Respir. 2010; 27: S79-105.

PubMed: https://pubmed.ncbi.nlm.nih.gov/20889026/

20. Severity Scoring of Atopic Dermatitis: The SCORAD Index. Dermatology. 1993; 186: 23-31.

PubMed: https://pubmed.ncbi.nlm.nih.gov/8435513/

21. Deschildre A, Lejeune S. How to cope with food allergy symptoms? Curr Opin Allergy Clin Immunol. 2018; 18: 234-242.

PubMed: https://pubmed.ncbi.nlm.nih.gov/29608467/

22. Sindher S, Long AJ, Purington N, Chollet M, Slatkin S, et al. Analysis of a Large Standardized Food Challenge Data Set to Determine Predictors of PositiveOutcomeAcross MultipleAllergens. FrontImmunol.2018;9:2689. PubMed: https://pubmed.ncbi.nlm.nih.gov/30538699/

23. Eigenmann PA, Lack G, Mazon A, Nieto A, Haddad D, Brough HA, et al. Managing Nut Allergy: A Remaining Clinical Challenge. J Allergy Clin Immunol Pract. 2017; 5: 296-300.

PubMed: https://pubmed.ncbi.nlm.nih.gov/27793601/

24. Ball H, Luyt D, Bravin K, Kirk K. Single nut or total nut avoidance in nut allergic children: outcome of nut challenges to guide exclusion diets: Oral nut challenges inform exclusion diets. Pediatr Allergy Immunol. 2011; 22: 808-812.

PubMed: https://pubmed.ncbi.nlm.nih.gov/21929602/

25. Niggemann B, Beyer K. Factors augmenting allergic reactions. Allergy. 2014; 69: 1582-1587.

PubMed: https://pubmed.ncbi.nlm.nih.gov/25306896/

26. Brough HA, Caubet J-C, Mazon A, Haddad D, Bergmann MM, et al. Defining challenge-proven coexistent nut and sesame seed allergy: A prospective multicenter European study. J Allergy Clin Immunol. 2020; 145: 1231-1239.

PubMed: https://pubmed.ncbi.nlm.nih.gov/31866098/

27. DunnGalvin A, Daly D, Cullinane C, Stenke E, Keeton D, et al. Highly accurate prediction of food challenge outcome using routinely available clinical data. J Allergy Clin Immunol. 2011; 127: 633-639. PubMed: https://pubmed.ncbi.nlm.nih.gov/21377032/

28. Yanagida N, Sato S, Takahashi K, Nagakura K, Asaumi T, et al. Increasing specific immunoglobulin $\mathrm{E}$ levels correlate with the risk of anaphylaxis during an oral food challenge. Pediatr Allergy Immunol. 2018; 29: 417-424.

PubMed: https://pubmed.ncbi.nlm.nih.gov/9575164/

29. Pettersson ME, Koppelman GH, Flokstra-de Blok BMJ, Kollen BJ, Dubois AEJ. Prediction of the severity of allergic reactions to foods. Allergy. 2018; 73: 1532-1540.

PubMed: https://pubmed.ncbi.nlm.nih.gov/29380392/

30. Mehta N, Devarakonda MV. Machine learning, natural language programming, and electronic health records: The next step in the artificial intelligence journey? J Allergy Clin Immunol. 2018; 141: 2019-2021. PubMed: https://pubmed.ncbi.nlm.nih.gov/29518424/

31. Messinger Al, Luo G, Deterding RR. The doctor will see you now: How machine learning and artificial intelligence can extend our understanding and treatment of asthma. J Allergy Clin Immunol. 2020; 145: 476-478.

PubMed: https://pubmed.ncbi.nlm.nih.gov/31883444/

32. Bird JA, Groetch M, Allen KJ, Bock SA, Leonard S, et al. Conducting an Oral Food Challenge to Peanut in an Infant. J Allergy Clin Immunol Pract. 2017; 5: 301-311.

PubMed: https://pubmed.ncbi.nlm.nih.gov/27838326/ 